\title{
High-Intensity Resistance Training Suppresses Exacerbation of Atopic Dermatitis in Mice
}

\author{
Eun-Ju Choi ${ }^{1} \mathrm{PhD}$, Ki Chan $\mathrm{Cho}^{2} \mathrm{PhD}$, Jooyoung $\mathrm{Kim}^{3} \mathrm{PhD}$ \\ ${ }^{1}$ Department of Physical Education, College of Education, Daegu Catholic University, Gyeongsan; ${ }^{2}$ Munji Elementary School, Daejeon; ${ }^{3}$ Office of Academic Affairs, \\ Konkuk University, Chungju, Korea
}

\begin{abstract}
PURPOSE: Training generally promotes health and inhibits diseases. However, in patients with atopic dermatitis (AD), training and sweating are significant aggravating factors. This study examined the effect of high-intensity resistance training (HIRT) on AD-like skin lesions in mice.
\end{abstract}

METHODS: Eight-week-old female BALB/c mice were divided into four groups (control, HIRT, AD-only, and AD + HIRT). The mice in the HIRT group performed vertical ladder climbing for four weeks.

RESULTS: After four weeks of HIRT, histopathological examination revealed reduced epidermis/dermis and dermal infiltration of inflammatory cells in the mice ear tissue. Additionally, HIRT suppressed serum immunoglobulin (Ig) levels and mRNA expression of pathogenic cytokines in the ear tissue; further, it reduced the size and weight of the draining lymph node (dLN) and non-dLN (ndLN), and the pathogenic cytokine-related mRNA expression of CD4+T cells from dLNs and ndLNs. We thus observed a negative correlation between HIRT and AD symptoms in mice.

CONCLUSIONS: The results show that HIRT exerts positive effects in patients with AD.

Key words: Atopic dermatitis, High-intensity resistance training, Immunoglobulin, Pathogenic cytokines, CE4+T cells

\section{INTRODUCTION}

Atopic dermatitis (AD) is a chronic inflammation of unidentified origin associated with dry skin, erythema, and eczema, and usually begins in early infancy but also affects a significant number of adults [1-3]. However, AD has been reported to be related to genetic and environmental factors such as allergens and microbes along with immune system and skin barrier dysfunction. It has also been reported that acute and chronic phase AD are strictly related to T helper 2 (Th2) and T helper 1 (Th1) cell-mediated AD lesions, respectively [3,4]. In addition, mast cell activation, elevated IgE levels, IgG and pro-inflammatory cytokines including interleukin (IL)-4, IL-13, IL-31, tumor necrosis factor-alpha (TNFa), and interferon-gamma (INF $\gamma$ ) play a vital role in skin abrasions [5-9]. Accordingly, the role of IL-17 has been suggested in certain skin conditions $[10,11]$.

Training is a well-known practice for maintaining good health and preventing diseases [12]. Regular training is effective in reducing the risk of coronary artery disease, stroke, hypertension, and osteoporosis [13] Meanwhile, it is plausible that AD patients do not training because of the itching due to sweating during training. This hypothesis is supported by previous studies by Stern et al. [14] and Williams et al. [15]. On the contrary, there is other aspect that regular physical activity may be beneficial to patients with $\mathrm{AD}$ [16]. In addition, to the best of our knowledge, the effect of high-intensity resistance training (HIRT) on AD has not yet been evaluated. In this study, therefore, we evaluated the effect of HIRT on $\mathrm{AD}$ lesions using $\mathrm{BALB} / \mathrm{c}$ mice.

Corresponding author: Jooyoung Kim Tel +82-43-840-3212 Fax +82-43-851-7950 E-mail hirase1125वhanmail.net

Received 13 Oct 2020 Revised 15 Nov 2020 Accepted 24 Nov 2020 


\section{METHODS}

\section{Animals}

Eight-week-old female BALB/c mice (Samtako, Osan, Republic of Korea) were housed under specific pathogen-free conditions. Five to ten mice per cage were housed in a laminar airflow room, maintained at a temperature of $22 \pm 2^{\circ} \mathrm{C}$ with a relative humidity of $55 \pm 5 \%$ throughout the study. All experiments were approved by the Institutional Animal Care and Use Committee of Konkuk University.

\section{Induction of $A D$ lesions in the ear and high-intensity resistance training protocol}

$\mathrm{AD}$ was induced in the mice by repeated local exposure of the ears to Dermatophagoides farinae extract (DFE; house dust mite extract) and 2,4-dinitrochlorobenzene (DNCB) as previously described [17]. For AD induction, the mice were divided into four groups (control, HIRT, ADonly, and $\mathrm{AD}+\mathrm{HIRT}$ ). The surfaces of both earlobes were stripped five times with surgical tape (Nichiban, Tokyo, Japan). After stripping, $20 \mu \mathrm{L}$ of $1 \%$ DNCB was applied on each ear, followed 4 days later by $20 \mu \mathrm{L}$ of DFE $(10 \mathrm{mg} / \mathrm{mL})$. DFE or DNCB treatment was administered alternately, once a week for 4 weeks.

The HIRT performed climbing of a vertical ladder for 4 weeks. The training was performed using a $1-\mathrm{m}$ ladder with a $1.5-\mathrm{cm}$ grid and in- clined at $85^{\circ}$ (Fig. 1A). Initially, the mice performed climbing with free weight for a week in order to get accustomed to the training. For the first training session, $10 \%$ of their body weight was attached to the base of their tails during a week of training, and the resistance was progressively increased to 0\% (2 times), 10\% (2 times), 30\% (2 times), and 50\% (2 times) during the next 2 weeks. For the last training session, 100\% of their body weight was attached to the base of their tails during a week.

\section{Ear thickness measurement and blood samples preparation}

Ear thickness was measured 24 hours after DNCB or DFE application with a dial thickness gauge (Kori Seiki MFG, Co., Japan). At days 14 and 28 , blood samples were collected via orbital puncture. Plasma samples were prepared from the blood samples and stored at $-70^{\circ} \mathrm{C}$ for further analysis. After blood collection, the ears were removed and used for histopathological analysis. Serum immunoglobulin (Ig) E and IgG2a levels were measured at days 14 and 28 after the first induction using an $\operatorname{IgE}$ enzyme-linked immunoassay kit (Bethyl Laboratories, Inc., Montgomery, TX, USA) according to the manufacturer's instructions.

\section{Histological observations}

The excised ears were fixed in 4\% paraformaldehyde for 16 hours and embedded in paraffin. Thin $(6 \mu \mathrm{m})$ sections were stained with hematox-
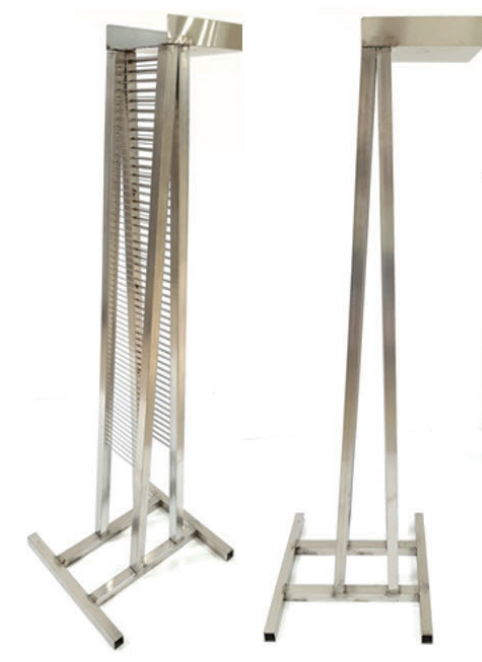

A

Fig. 1. (A) Ladder for high-intensity resistance training (HIRT). (B) Experimental schedule for the induction of AD lesion. (C) The mice performed climbing of the vertical ladder for 4 weeks. The training was accomplished using a 1-m ladder with a $1.5-\mathrm{cm}$ grid and inclined at $85^{\circ}$. Initially, the mice performed climbing with free weight for a week in order to become accustomed to the weight. For the first training session, a free weight, which was $10 \%$ of the body weight, was attached to the base of their tails, and the resistance was progressively increased to $30 \%$ and $50 \%$ during the 4 weeks. 
ylin and eosin (H\&E). The thickness of the epidermis and dermis was measured under a microscope. For measurement of mast cell infiltration, skin sections were stained with toluidine blue, after which the number of mast cells was counted in five randomly chosen fields of view.

\section{Real-time polymerase chain reaction (PCR)}

Quantitative real-time PCR was carried out using a Thermal Cycler Dice TP850 (Takarabio Inc., Shiga, Japan) according to the manufacturer's protocol. Total RNA was isolated from the ear tissue and lymph nodes of each group. The PCR conditions were similar to those previously described [17]. Two microliters of cDNA (100 ng), $1 \mu \mathrm{L}$ of sense and antisense primer solution $(0.4 \mu \mathrm{M}), 12.5 \mu \mathrm{L}$ of SYBR Premix Ex Taq (Takarabio Inc.), and $9.5 \mu \mathrm{L}$ of $\mathrm{dH}_{2} \mathrm{O}$ were mixed to obtain a final $25-\mu \mathrm{L}$ reaction mixture in each reaction tube. The amplification conditions were as follows: 10 seconds at $95^{\circ} \mathrm{C}, 40$ cycles of 5 seconds at $95^{\circ} \mathrm{C}$ and 30 seconds at $60^{\circ} \mathrm{C}, 15$ seconds at $95^{\circ} \mathrm{C}, 30$ seconds at $60^{\circ} \mathrm{C}$, and $15 \mathrm{sec}-$ onds at $95^{\circ} \mathrm{C}$. The mRNA levels of the target genes relative to glyceraldehyde 3-phosphate dehydrogenase (GAPDH) were normalized using the following formula: relative mRNA expression $=2^{- \text {(Ct of target gene-Ct of GAPDH) }}$, where
$C t$ is the threshold cycle value. In each sample, the expression level of the analyzed gene was normalized to that of GAPDH and presented as a relative mRNA level.

\section{Statistical analysis}

Statistical analysis was carried out using SAS statistical software (SAS Institute, Cary, NC, USA). Multiple group data were analyzed using oneway analysis of variance followed by Dunnett's multiple range test. All results are expressed as the mean \pm standard deviation of comparative fold differences. Data are representative of three independent experiments. The threshold for significance was set at $p<.05$.

\section{RESULTS}

After HIRT for 4 weeks, we observed that AD+ HIRT significantly reduced the thickness of both the right and left ears (Fig. 2A, B) $(p<.05)$. Also, a reduced number of infiltrated mast cells was found in the $\mathrm{AD}+\mathrm{HIRT}$ group mice, compared with the AD group (Fig. 3A, C, and D). Furthermore, AD + HIRT suppressed the thickness of epidermal and dermal cells (Fig. 3B). We found a reduced number of mast cells in the

Right ear

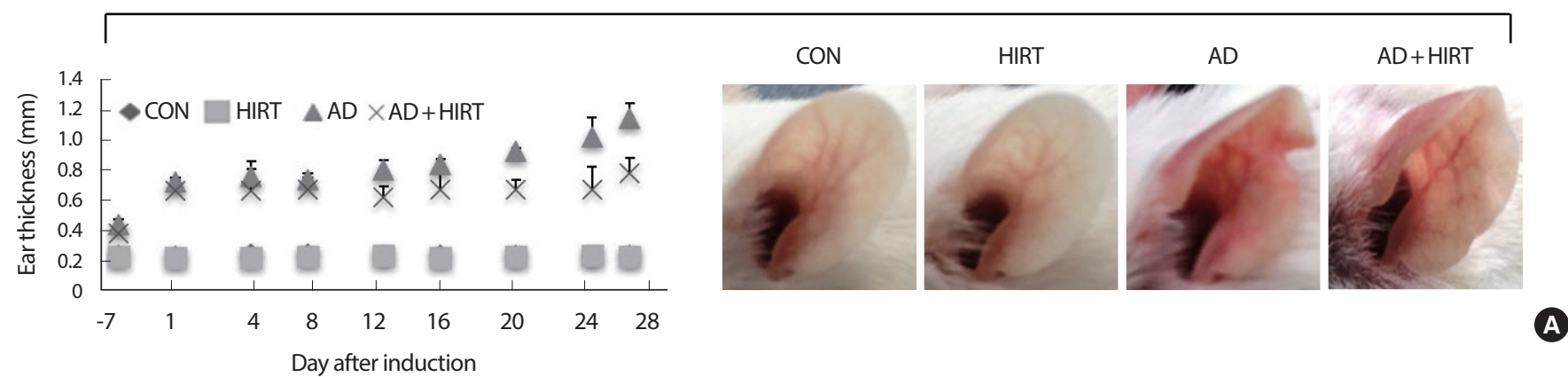

Left ear
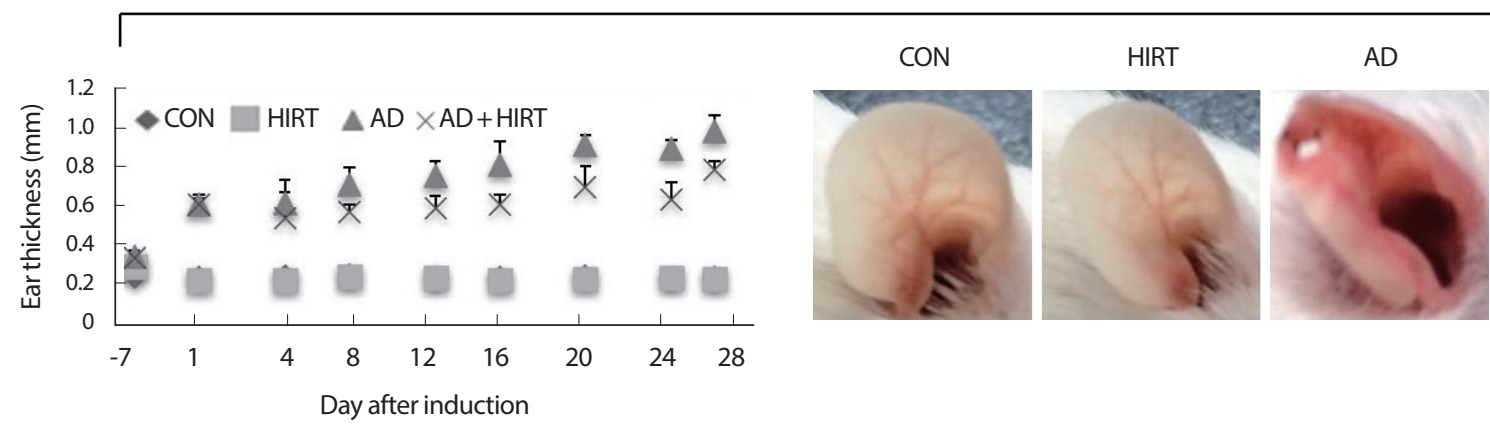

$\mathrm{AD}+\mathrm{HIRT}$

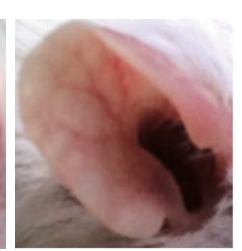

Fig. 2. Photographs of the ears of mice from each group on day 28. (A) Right ear (B) left ear thickness was measured with a dial thickness gauge every 3 days after 2,4-dinitrochlorobenzene (DNCB) or Dermatophagoides farinae extract (DFE) application. *indicates a significant difference from the value of the DFE/DNCB-treated mice at $p<.05$. AD, atopic dermatitis; HIRT, high-intensity resistance training. 

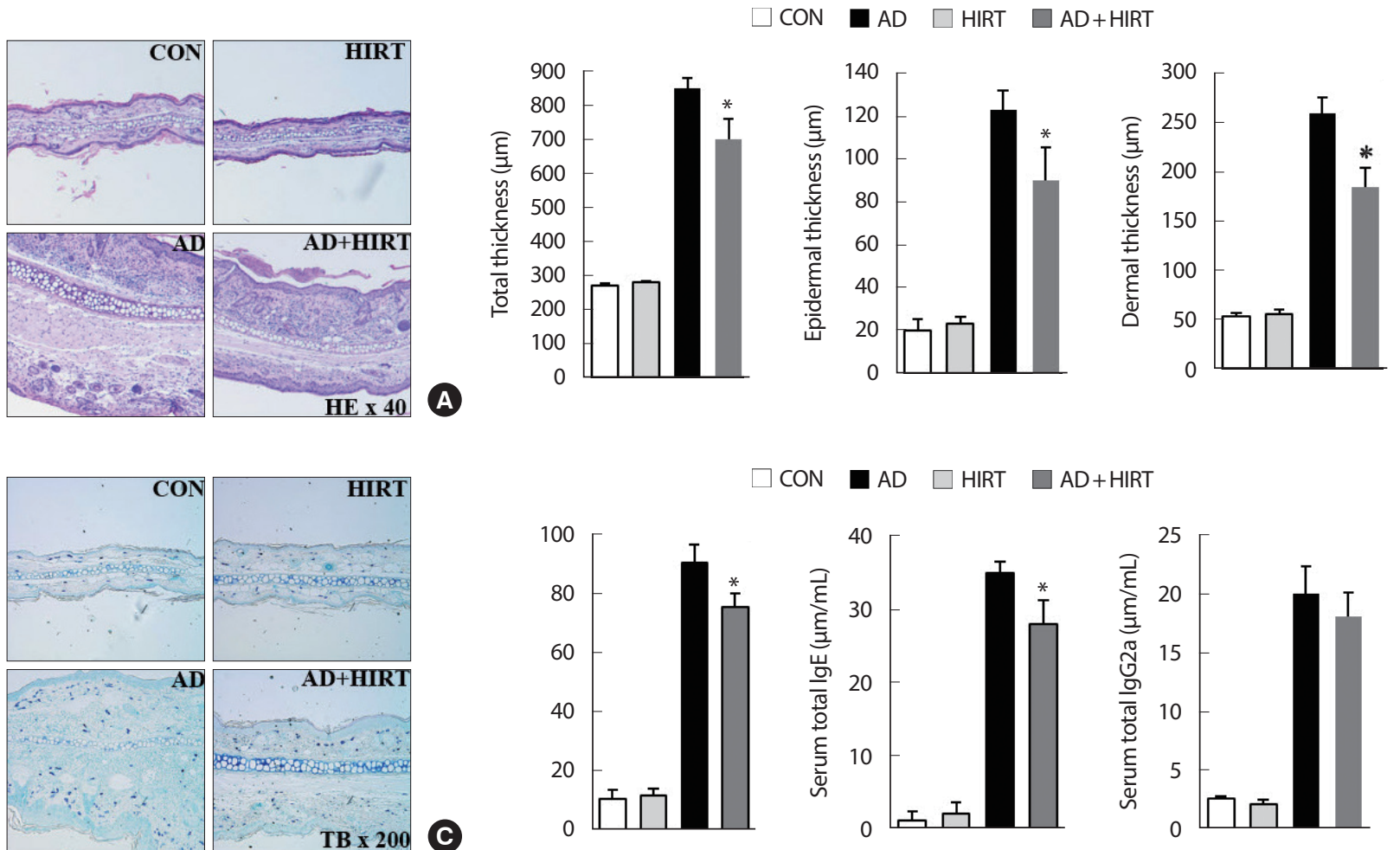

HIRT

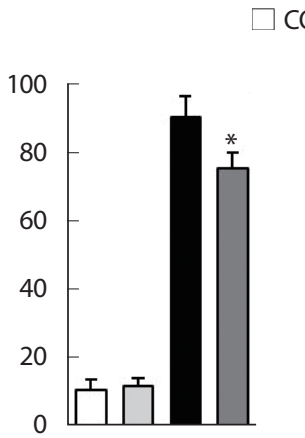

CON

AD $\square$ HIRT

$A D+H I R T$
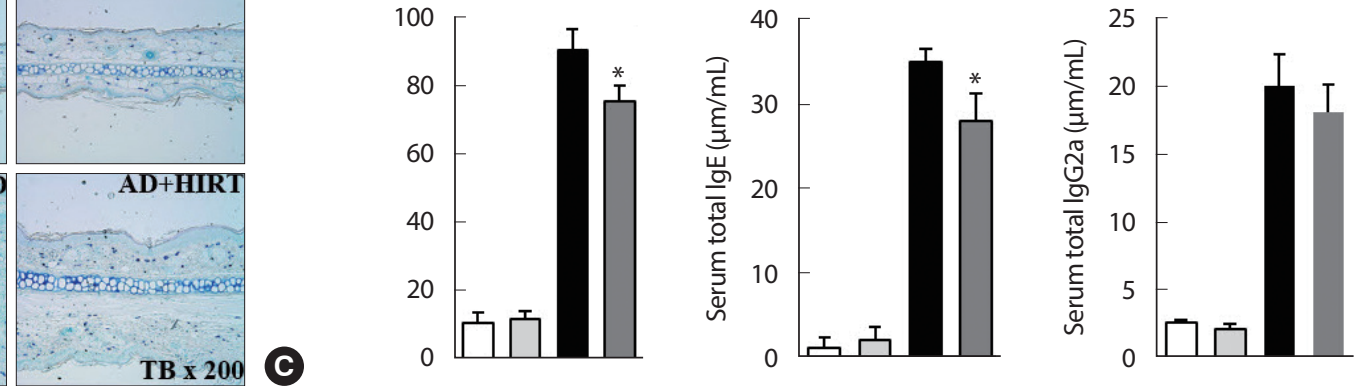

D

Fig. 3. Representative photomicrographs of ear sections stained with hematoxylin and eosin (A) or toluidine blue (B). Epidermal and dermal thickness were measured using microphotographs of hematoxylin and eosin-stained-tissue (C). The number of infiltrated mast cells was determined based on toluidine blue staining (D). Blood samples were collected via orbital puncture at day 28. Plasma IgE (E) and lgG2a (F) levels were quantified using enzymelinked immunosorbent assay. Data are presented as the mean $\pm S D$ of triplicate determinations. *indicates a significant difference from the value of the DFE/DNCB-treated mice at $p<.05$. AD induced by DFE and DNCB treatment. The pictures shown are representative of each group $(n=3-6)$. The original magnification was $100 \times C O N$. AD, atopic dermatitis; HIRT, high-intensity resistance training.

AD + HIRT group mice (Fig. 3B).

AD + HIRT significantly suppressed the expression of Th2-related cytokines such as IL-4, IL-6, IL-10, IL-13, and IL-31 as well as Th1-related cytokine such as IFN- $\gamma$ in the ear tissue (Fig. 4). We evaluated the size and weight of dLN and ndLN as well as the cytokine-related mRNA expression of CD4 +T cells from dLN and ndLN cells. The AD mice had bigger dLN compared with the healthy untreated control mice (Fig. 5A). The size of dLN were reduced after 4 weeks of HIRT (Fig. 5A). However, no significant changes were observed among the four groups of mice regarding their ndLN size (Fig. 5B). Investigation of the inflammatory mRNA-related cytokines from CD4+T cells purified from dLN revealed that the mice in the AD+HIRT group had a significantly lower expression of IL-4, L-17, and I INF $\gamma$ (Fig. 5A). However, the AD + HIRT group mice did not affect mRNA expression of IL-4, L-17, and I INF $\gamma$ in the CD4+T cells purified from their ndLNs (Fig. 5B).

\section{DISCUSSION}

Training is necessary for a healthy life. Regular training not only improved antioxidant activities and immunity but also reduced the danger of some diseases [13,18,19]. However, Williams et al. [15] and Stern et al. [14] reported that training that cause sweating were notable AD worsening factors in schoolchildren. Accordingly, researchers have also reported that training, heat, and sweating, caused the most discomfort for schoolchildren with AD in Singapore [20]. Nevertheless these previous studies, there were little investigation systemic analysis of the effect of high intensity training on $\mathrm{AD}$. Afterward, we hypothesize that training may have positive effect on AD patients. Thus, in the present study, we evaluated the effect of HIRT on rat models with AD. To examine the immunomodulatory properties of HIRT, the mice performed climbing of a vertical ladder for 4 weeks. After HIRT for 4 weeks, we observed ear thickness, inflammatory cell infiltration, IgE and IgG2a expression in serum, mRNA level of immunoregulatory cytokines in the ear tissue 


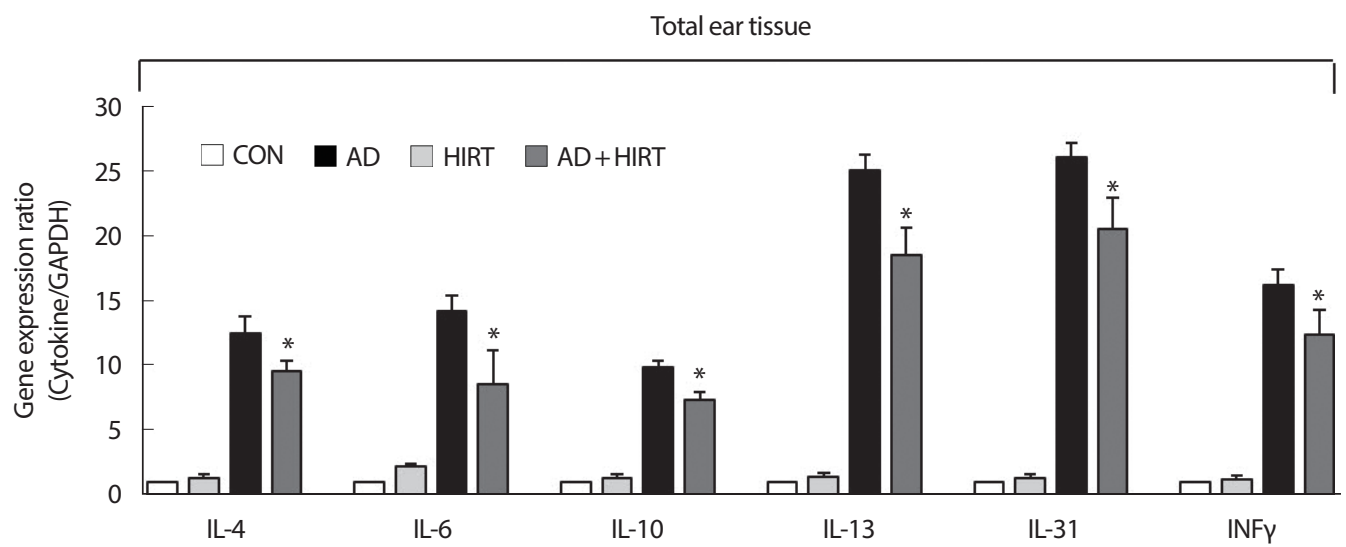

Fig. 4. Effect of high-intensity resistance training (HIRT) on the expression of various pathogenic factors in the ear. The ears were excised on day 28 and total RNA was isolated. Quantitative real-time polymerase chain reaction was performed as described in the Methods section. Data is presented as the mean \pm SD of triplicate determinations. *indicates a significant difference from the value of the DFE/DNCB-treated mice at $p<.05$. AD induced by DFE and DNCB treatment. DNCB, 2,4-dinitrochlorobenzene; DFE, Dermatophagoides farina extract; CON, control; AD, atopic dermatitis.
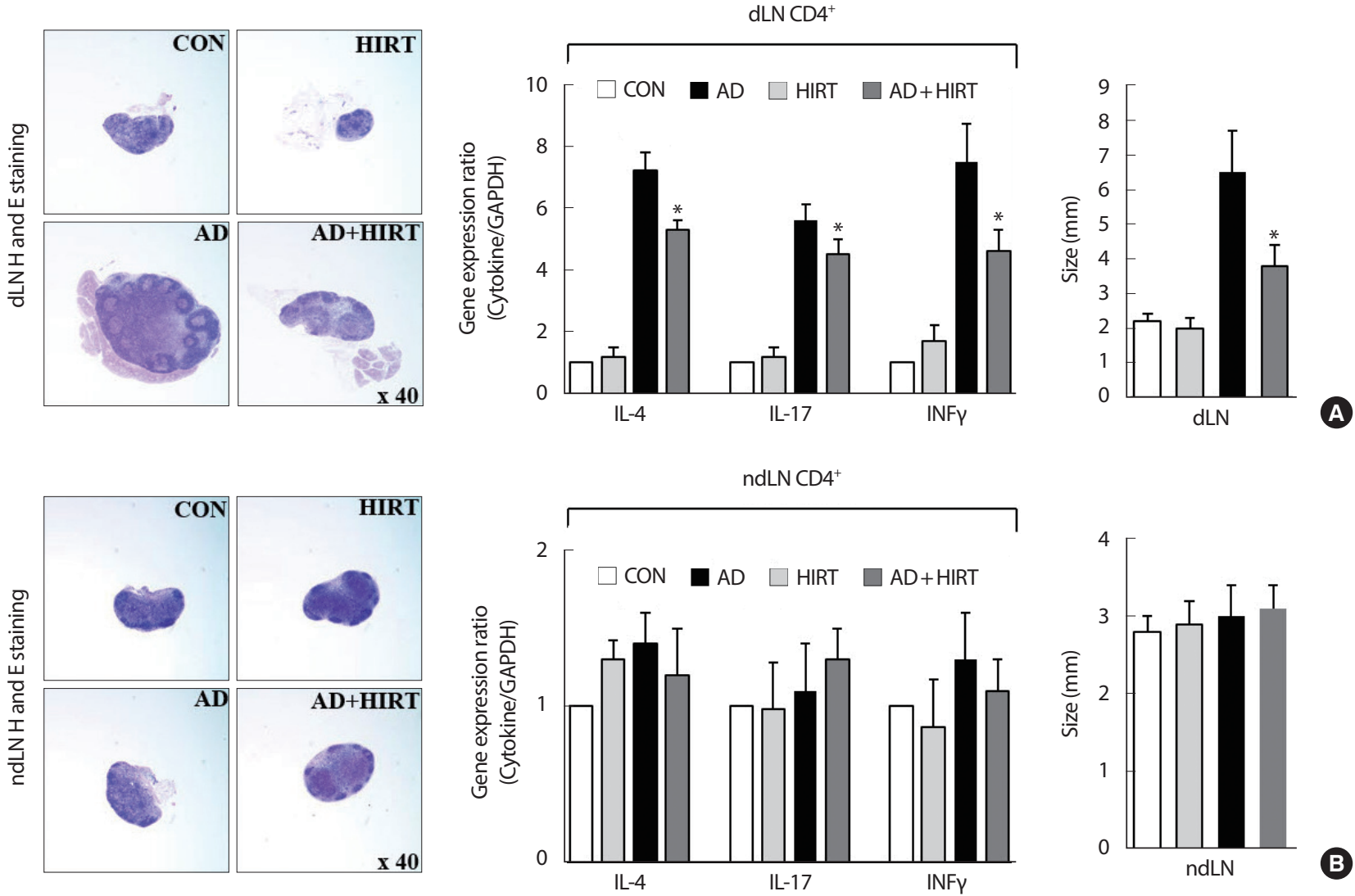

Fig. 5. Effect of high-intensity resistance training (HIRT) on the expression of size of draining lymph node (dLN) and non-dLN (ndLN), and the cytokine-related mRNA expression of CD4+T cells from the dLN (A) and ndLN (B). *indicates a significant difference from the value of the DFE/DNCB-treated mice at $p<.05$. AD induced by DFE and DNCB treatment. DNCB, 2,4-dinitrochlorobenzene; DFE, Dermatophagoides farina extract; CON, control; AD, atopic dermatitis.

and the size, weight of dLN and ndLN, and pathogenic cytokine-related mRNA expression of CD4+T cells from dLNs and ndLNs. The crosslinking of IgE and allergen stimulates the mast cells that release cytokines at the sites of allergic reactions [21]. Further, increased levels of IgG antibodies have been reported to play a role in $\mathrm{AD}$ and have been associated with Th1 response [22]. A number of studies have reported that AD shows increased total IgE level and Th2/Th1-type cytokine expression [23-26]. To define whether AD exerts its effects mainly via Th1 or Th2 re- 
sponse, serum levels of IgE (total and DFE-specific) and IgG2a were measured in each treatment group and reduced total IgE and IgG2a levels were observed in $\mathrm{AD}+\mathrm{HIRT}$ group mice, compared with those of the DFE/DNCB-treated mice. These results propose that the effect HIRT on $\mathrm{AD}$ development is related with the downregulation of serum Ig levels.

When pathogens are encountered, naive CD4+T cells lead to the generation of Th1 and Th2 cells. Th2 cells produce IL-4, IL-13, and IL-17, which encourage humoral immunity and produces IgE as well as control Th1 response [27]. In particular, IL-4 plays an important role in the transformation of naive CD4+T cells into Th2 cells [28]. Furthermore, AD has been reported as a systemic disease [29]. Therefore, we further examined whether HIRT affects systemic immune responses. In a previous study using NC/Nga mice, it was revealed that AD-like symptoms were promoted by strong training and reduced by mild training [30]. Accordingly, Kim et al. [17]. reported that AD symptoms increased with high-intensity swimming training in $\mathrm{BALB} / \mathrm{c}$ mice with higher IgE levels and cytokines expression. Differing to these investigations, our study shows that HIRT suppressed AD symptoms.

\section{CONCLUSIONS}

We found that the severity of AD evidenced by histopathological signs, IgE, IgG levels, and expression of mRNA of pathogenic cytokines in the ear tissue was suppressed by HIRT. In addition, HIRT reduced the size of $\mathrm{dLN}$, and pathogenic cytokine-related mRNA expression of CD4 + T cells from dLNs, whereas the weight and size of ndLN were not significantly different. This results suggests that HIRT could be beneficial for people with AD.

\section{ACKNOWLEDGEMENTS}

This work was supported by research grants from Daegu Catholic University in 2018.

\section{CONFLICTS OF INTEREST}

The authors declare no conflict of interest.

\section{AUTHOR CONTRIBUTION}

Conceptualization: E Choi, J Kim; Data curation: KC Cho; Formal analysis: E Choi, KC Cho; Methodology: E Choi, KC Cho; Visualization: KC Cho; Writing-original draft: E Choi, J Kim.

\section{ORCID}
Eun-Ju Choi
https://orcid.org/0000-0001-8205-5846
Ki Chan Cho
https://orcid.org/0000-0002-4623-9768
Jooyoung Kim
https://orcid.org/0000-0002-8755-1918

\section{REFERENCES}

1. Leung DY, Boguniewicz M, Howell MD, Nomura I, Hamid QA. New insights into atopic dermatitis. J Clin Invest. 2004;113(5):651-7.

2. Boguniewicz M, Leung DY. Recent insights into atopic dermatitis and implications for management of infectious complications. J Allergy Clin Immunol. 2010;125(1):4-13.

3. Savinko T, Matikainen S, Saarialho-Kere U, Lehto M, Wang G, et al. IL-33 and ST2 in atopic dermatitis: expression profiles and modulation by triggering factors. J Invest Dermatol. 2012;132(5):1392-400.

4. Nilsson OB, Adedoyin J, Rhyner C, Neimert-Andersson T, Grundström J, et al. In vitro evolution of allergy vaccine candidates, with maintained structure, but reduced b cell and t cell activation capacity. PLoS One. 2011;6(9):24558.

5. Niebuhr M, Werfel T. Innate immunity, allergy and atopic dermatitis. Curr Opin Allergy Clin Immunol. 2010;10(5):463-8.

6. Parisi CA, Smaldini PL, Gervasoni ME, Maspero JF, Docena GH. Hypersensitivity reactions to the Sabin vaccine in children with cow's milk allergy. Clin Exp Allergy. 2013;43(2):249-54.

7. Yamada N, Wakugawa M, Kuwata S, Yoshida T, Nakagawa H. Chronologic analysis of in situ cytokine expression in mite allergen-induced dermatitis in atopic subjects. J Allergy Clin Immunol. 1995;96(6 Pt 2):1069-75

8. Vestergaard C, Yoneyama H, Murai M, Nakamura K, Tamaki K, et al. Overproduction of Th2-specific chemokines in NC/Nga mice exhibiting atopic dermatitis-like lesions. J Clin Invest. 1999;104(8):1097-105.

9. Bilsborough J, Leung DY, Maurer M, Howell M, Boguniewicz M, et al. IL-31 is associated with cutaneous lymphocyte antigen-positive skin homing t cells in patients with atopic dermatitis. J Allergy Clin Immunol. 2006;117(2):418-25.

10. Albanesi C, Cavani A, Girolomoni G. IL-17 is produced by nickelspecific $t$ lymphocytes and regulates ICAM-1 expression and chemo- 
kine production in human keratinocytes: synergistic or antagonist effects with IFN-gamma and TNF-alpha. J Immunol. 1999;162(1):494502 .

11. Zheng Y, Danilenko DM, Valdez P, Kasman I, Eastham-Anderson J, et al. Interleukin-22, a T(H)17 cytokine, mediates IL-23-induced dermal inflammation and acanthosis. Nature. 2007;445(7128):648-51.

12. Haskell WL, Lee IM, Pate RR, Powell KE, Blair SN, et al. Physical activity and public health: updated recommendations for adults from the american college of sports medicine and the american heart association. Circulation. 2007;116(9):1081-93.

13. Booth FW, Lees SJ. Fundamental questions about genes, inactivity, and chronic diseases. Physiol Genomics. 2007;28(2):146-57.

14. Stern UM, Salzer B, Schuch S, Hornstein OP. Sex-dependent differences in sweating of normal probands and atopic patients in cardiovascular stress. Hautarzt. 1998;49(3):209-15.

15. Williams JR, Burr ML, Williams HC. Factors influencing atopic dermatitis-a questionnaire survey of schoolchildren's perceptions. $\mathrm{Br} \mathrm{J}$ Dermatol. 2004;150(6):1154-61.

16. Salzer B, Schuch S, Rupprecht M, Hornstein OP. Group sports as adjuvant therapy for patients with atopic eczema. Hautarzt. 1994;45(11): $751-5$.

17. Kim SH, Kim EK, Choi EJ. High-intensity swimming exercise increases dust mite extract and 1-chloro-2,4-dinitrobenzene-derived atopic dermatitis in BALB/c mice. Inflammation. 2014;37(4):1179-85.

18. Sen CK. Glutathione homeostasis in response to exercise training and nutritional supplements. Mol Cell Biochem. 1999;196(1-2):31-42.

19. Sen CK, Packer L. Thiol homeostasis and supplements in physical exercise. Am J Clin Nutr. 2000;72(2):653-69.

20. Tay YK, Kong KH, Khoo L, Goh CL, Giam YC. The prevalence and descriptive epidemiology of atopic dermatitis in Singapore school chil- dren. Br J Dermatol. 2002;146(1):101-6.

21. Borish L, Joseph BZ. Inflammation and the allergic response. Med Clin North Am. 1992;76(4):765-87.

22. Mathlouthi M, Koenig JL. Vibrational spectra of carbohydrates. Adv Carbohydr Chem Biochem. 1986;44:7-89.

23. Grewe M, Bruijnzeel-Koomen CA, Schopf E, Thepen T, LangeveldWildschut AG, et al. A role for Th1 and Th2 cells in the immunopathogenesis of atopic dermatitis. Immunol Today. 1998;19(8):359-61.

24. Hamid Q, Boguniewicz M, Leung DY. Differential in situ cytokine gene expression in acute versus chronic atopic dermatitis. J Clin Invest. 1994;94(2):870-6.

25. Chen L, Martinez O, Overbergh L, Mathieu C, Prabhakar BS, et al. Early up-regulation of Th2 cytokines and late surge of Th1 cytokines in an atopic dermatitis model. Clin Exp Immunol. 2004;138(3):37587.

26. Neis MM, Peters B, Dreuw A, Wenzel J, Bieber T, et al. Enhanced expression levels of IL-31 correlate with IL-4 and IL-13 in atopic and allergic contact dermatitis. J Allergy Clin Immunol. 2006;118(4):930-7.

27. Abbas AK, Murphy KM, Sher A. Functional diversity of helper tymphocytes. Nature. 1996;383(6603):787-93.

28. Rincón M, Anguita J, Nakamura T, Fikrig E, Flavell RA. Interleukin (IL)-6 directs the differentiation of IL-4-producing CD4+ t cells. J Exp Med. 1997;185(3):461-9.

29. Darlenski R, Kazandjieva J, Hristakieva E, Fluhr JW. Atopic dermatitis as a systemic disease. Clin Dermatol. 2014;32(3):409-13.

30. Hiramoto K, Kobayashi H, Sekiyama A, F Sato E, Tsuruta D, et al. Mild exercise suppresses exacerbation of dermatitis by increasing cleavage of the $\beta$-endorphin from proopiomelanocortin in $\mathrm{NC} / \mathrm{Nga}$ mice. J Clin Biochem Nutr. 2013;52(1):58-63. 